\title{
CARACTERIZAÇÃO FÍSICO-QUÍMICA E MICROESTRUTURAL DE CONCHAS DE MOLUSCOS BIVALVES PROVENIENTES DE CULTIVOS DA REGIÃO LITORÂNEA DA ILHA DE SANTA CATARINA
}

\author{
Denyo Silva e Nito Angelo Debacher* \\ Departamento de Química, Universidade Federal de Santa Catarina, 88040-900 Florianópolis - SC, Brasil \\ Armando Borges de Castilhos Junior e Fabio Rohers \\ Departamento de Engenharia Sanitária e Ambiental, Universidade Federal de Santa Catarina, 88040-970 Florianópolis - SC, Brasil
}

Recebido em 9/7/08; aceito em 13/1/10; publicado na web em 3/5/10

\begin{abstract}
PHYSICAL CHEMISTRY AND MICRO STRUCTURAL CHARACTERIZATION OF SHELLS OF BIVALVE MOLLUSKS FROM SEA FARMER AROUND THE SANTA CATARINA ISLAND. Samples of shells of oysters and mussels from sea farm around the Santa Catarina Island in south Brazil were collected and analyzed by DRX, FRX, SEM, CHN-S, FTIR, TG, AAS/Flame and AAS / GF. The results showed that the crystalline structure of mussel's shells is mainly formed by aragonite and the oyster's shells by calcite. The calcium percentage in both shells species was in the range of 33 to $35 \%$ and also 850 and $1200 \mathrm{mg} / \mathrm{kg}$ of strontium was detected in the shells of oysters and mussels, respectively. The content of organic matter was larger in the mussel's shells and the thermal degradation of both shells species occurred by three events at different temperatures from 250 to $830{ }^{\circ} \mathrm{C}$.
\end{abstract}

Keywords: oyster shell; mussel shell; waste of malacoculture.

\section{INTRODUÇÃO}

A maricultura constitui um dos setores produtivos em expansão do Estado de Santa Catarina, que apresenta um litoral com inúmeras áreas protegidas formado por baías, enseadas e estuários de águas frias, favorecendo o cultivo principalmente de moluscos. As espécies mais cultivadas são os moluscos bivalves da família Mitilidae, representada pelo mexilhão nativo perna perna ${ }^{1}$ e da família Ostreidae, representada pela ostra do pacífico (exótica) Crassostrea gigas. ${ }^{2} \mathrm{~A}$ maior produção de ostras do Brasil localiza-se em torno da Ilha de Santa Catarina, município de Florianópolis, respondendo por mais de 1 milhão de dúzias, ou seja, $80 \%$ da produção nacional correspondendo a $14.756,9$ toneladas em $2006 .{ }^{3}$

Os moluscos desenvolvem exoesqueleto rígido em forma de concha para se proteger de predadores e suportar a pressão hídrica do meio aquático em que habitam. As conchas são basicamente formadas pela deposição contínua do nácar pelo próprio molusco a partir da superfície interna da concha onde se desenvolve, proporcionando um mecanismo de defesa contra parasitas e uma forma de manter a área lisa e livre de corpos estranhos como grãos de areia. ${ }^{4}$

O nácar é uma substância dura e brilhante composta de camadas de conchiolina, uma escleroproteína complexa formada de queratina, colágeno e elastina secretada pelo molusco e intercalada por camadas de calcita ou aragonita, (cristais de carbonato de cálcio) proporcionando alta dureza e rigidez à concha. ${ }^{4,5}$ Além do cálcio, vários outros elementos podem ser incorporados à estrutura das conchas, cujas porcentagens variam e podem estar relacionados à temperatura, $\mathrm{pH}$, salinidade e concentração destes componentes na água do meio em que habitam. Desta forma, as conchas de moluscos bivalves podem ser usadas como bioindicadores para detectar modificações na composição da água por atividades antropogênicas ou de origem natural por atividades geológicas. ${ }^{6,7}$

Os moluscos são muito apreciados na culinária sendo uma fonte de proteína importante, no entanto, a concha que consiste em mais de $70 \%$ de seu peso não serve para consumo humano, resultando em um passivo ambiental considerável. Embora as conchas não se-

\footnotetext{
*e-mail: debacher@qmc.ufsc.br
}

jam resíduos potencialmente perigosos, sua disposição em grandes quantidades de forma inadequada ocasiona impactos e, em consequência, problemas ambientais. Porém, este resíduo pode ser fonte de matéria- prima em vários processos desde que suas propriedades físico-químicas sejam conhecidas. ${ }^{8,9}$ Conchas de ostras pirolisadas por $1 \mathrm{~h}$ à temperatura de $750^{\circ} \mathrm{C}$, por exemplo, podem ser utilizadas como adsorvente no tratamento de efluentes com elevada concentração de fosfato, ou como fonte de óxido de cálcio para a construção civil. ${ }^{8}$

$\mathrm{O}$ trabalho tem como objetivo determinar a estrutura cristalina, a composição química e as propriedades físicas das conchas de ostra Crassostrea gigas e mexilhão Perna perna provenientes de cultivos da região litorânea próxima à Ilha de Santa Catarina.

\section{PARTE EXPERIMENTAL}

\section{Amostragem}

As amostras de conchas de ostras e mexilhões foram coletadas em três pontos de cultivo da região litorânea próxima da Ilha de Santa Catarina, situados nos municípios de Governador Celso Ramos na localidade de Ganchos de Fora; Palhoça na localidade de Enseada do Brito e em Florianópolis na localidade de Sambaqui. As coordenadas geográficas dos pontos amostrados são: a) Sambaqui: Latitude: 27²9'18'S - Longitude: 48³2'18”'O; b) Ganchos de Fora: Latitude: $27^{\circ} 18$ '23”S - Longitude: 48³2'54”'O; c) Enseada do Brito: Latitude: 2747'36'S - Longitude: 48³7'53'’.

\section{Procedimentos analíticos}

Para os ensaios de caracterização das amostras as técnicas analíticas e equipamentos utilizados foram os seguintes: espectrometria de absorção atômica com atomização em chama (EAA-Chama) para determinação dos metais majoritários, conduzida em equipamento marca Hitachi mod. Z8200; espectrometria de absorção atômica com atomização em forno de grafite (EAA-FG) para determinação dos metais minoritários, conduzida em equipamento marca Varian mod. 640Z; espectrometria de fluorescência de raios X (FRX) para determinação dos óxidos, conduzida em equipamento marca Phillips, 
mod. PW2400; analisador elementar (CHN-S) para determinação de carbono, hidrogênio, nitrogênio e enxofre, conduzidas em equipamento marca Carlo Erba, mod. EAW 1110; microscopia eletrônica de varredura (MEV) para obtenção das micrografias superficiais, conduzidas em equipamento marca Phillips mod. XL30. As análises químicas superficiais foram conduzidas em equipamento EDAX mod. New XL30; difração de raios X (DRX) para determinação da estrutura cristalina, conduzida em equipamento marca Philips mod. X'Pert, com detector de radiação cobre $\mathrm{K} \alpha, \lambda 1,5406 \AA ̊$; espectrometria no infravermelho (IV) para identificação de grupos funcionais, conduzida em equipamento marca Perkin Elmer, mod. FTIR-16PC; termogravimetria (TGA) para determinação de degradação térmica, teor de cinzas e matéria orgânica, conduzida em equipamento marca Shimadzu mod. TGA-50 com atmosfera inerte de $\mathrm{N}_{2}$.

\section{Preparo das amostras}

As conchas foram lavadas em água corrente, secas naturalmente, britadas e moídas em gral de ágata e posteriormente classificadas em malha 80 mesh $(0,18 \mathrm{~mm})$. A seguir, apresenta-se em detalhes o prétratamento aplicado às amostras nas diferentes técnicas de análise.

Para as análises das amostras através de EAA-Chama e EAAFG, para determinação dos metais $\mathrm{Ca}, \mathrm{Mg}, \mathrm{Fe}, \mathrm{Mn}, \mathrm{Zn}, \mathrm{Sr}, \mathrm{Na}, \mathrm{K}$, $\mathrm{Ni}, \mathrm{Cu}, \mathrm{Cd}, \mathrm{Pb}$ e $\mathrm{Cr}$ foi feita a digestão ácida a quente de $0,3 \mathrm{~g}$ da amostra e adicionados $10 \mathrm{~mL}$ de $\mathrm{HNO}_{3}$ mais $1 \mathrm{~mL}$ de $\mathrm{H}_{2} \mathrm{O}_{2}(120 \mathrm{~V})$. A seguir, a mistura foi ultrassonicada por $15 \mathrm{~min}$ e aquecida a $70^{\circ} \mathrm{C}$ por $30 \mathrm{~min}$, depois resfriada a temperatura ambiente e o conteúdo avolumado para $250 \mathrm{~mL}$ em um balão volumétrico.

Para as análises das amostras através de RX; CHN-S; DRX; IV; TGA, da composição química, da degradação térmica, da estrutura cristalina e dos óxidos metálicos usaram-se amostras na fase sólida com granulometria de 80 mesh.

Para as análises das amostras através de MEV e energia dispersiva de raios $\mathrm{X}$ usaram-se amostras sólidas em tamanho natural sem tratamento prévio.

Os ensaios de densidade aparente (bulk density) foram realizados segundo método ASTM D1895. Os ensaios de $\mathrm{pH}$ foram conduzidos em equipamento Orion mod. 920A numa suspensão em água a $10 \%$ $\mathrm{p} / \mathrm{V}$ da amostra com granulometria de 80 mesh.

\section{RESULTADOS E DISCUSSÃO}

\section{Caracterização química}

\section{Análise elementar (CHN-S)}

A Tabela 1 mostra os resultados obtidos por análise elementar (CHN-S) das diferentes amostras de conchas de ostras e de mexilhões.

$\mathrm{O}$ teor médio de carbono encontrado nas amostras de conchas foi de $12 \%$ para as conchas de ostra e de $13,5 \%$ para as conchas de mexilhões. A porcentagem de nitrogênio foi quatro vezes $(0,84 \%$, média) maior nas conchas de mexilhões do que nas das ostras e o hidrogênio foi detectado apenas nas conchas de mexilhões $(0,55 \%$, média). A presença de nitrogênio na amostra indica a existência do grupo amino na fração orgânica, derivado de proteínas responsáveis pela biomineralização do carbonato de cálcio das conchas. ${ }^{5} \mathrm{~A}$ ausência de hidrogênio e a menor porcentagem de nitrogênio e carbono nas conchas de ostras indicam menor quantidade de matéria orgânica na sua composição. O enxofre não foi detectado nas amostras.

Os teores de carbono, nitrogênio e hidrogênio são superiores nas conchas de mexilhões em comparação às conchas de ostras.

\section{Análise por espectroscopia de absorção no infravermelho}

As análises por espectrometria no infravermelho (IV) em pastilhas de $\mathrm{KBr}$ realizadas com amostras de conchas de ostras (Figura 1A) e mexilhões (Figura 1B) foram comparadas com padrão de carbonato de cálcio Aldrich 99\% P.A (Figura 1C).

As atribuições dos modos vibracionais observados nos espectros no infravermelho nas amostras de conchas de ostras (Figura 1A), referente à fração calcita, foram as seguintes: deformações angulares no plano $\delta_{d}(\mathrm{OCO})$ em $712 \mathrm{~cm}^{-1}$; deformações angulares fora do plano $\gamma\left(\mathrm{CO}_{3}\right)$ em $873 \mathrm{~cm}^{-1}$ e estiramento antissimétrico $v_{\text {as }}(\mathrm{CO}) \mathrm{em}$ $1420 \mathrm{~cm}^{-1}$.

As atribuições dos modos vibracionais observados nos espectros no infravermelho nas amostras de conchas de mexilhões, (Figura 1B), referente à fração aragonita, foram as seguintes: estiramento simétrico $v_{\mathrm{s}}(\mathrm{CO})$ em $1078 \mathrm{~cm}^{-1}$; estiramento antissimétrico $\mathrm{v}_{\mathrm{as}}(\mathrm{CO})$ em $1464 \mathrm{~cm}^{-1}$; deformações angulares fora do plano $\gamma\left(\mathrm{CO}_{3}\right) \mathrm{em} 856$ $\mathrm{cm}^{-1}$; deformações angulares no plano $\delta_{\mathrm{d}}(\mathrm{OCO}) \mathrm{em} 704 \mathrm{~cm}^{-1}$.

O padrão de carbonato (Figura 1C) apresentou bandas de absorção em 856, 708, 1080 e $1492 \mathrm{~cm}^{-1}$ similar aos padrões de aragonita, que apresenta espectros com absorção característicos em 1474, 1080, 854, 712 e $700 \mathrm{~cm}^{-1} .^{10,11}$ Padrões de calcita apresentam absorções muito similares no infravermelho, absorvendo em 1420, 874 e 712/700 $\mathrm{cm}^{-1} .9$

As principais diferenças nas amostras analisadas de conchas de mexilhões e ostras encontram-se nas bandas de absorção que caracterizam calcita e aragonita. As conchas de ostras apresentaram bandas no infravermelho em 712, 873 e $1420 \mathrm{~cm}^{-1}$ correspondentes ao $\mathrm{CaCO}_{3}$ na forma de calcita e as conchas de mexilhões, bandas no infravermelho em 704 e $856 \mathrm{~cm}^{-1}, 1080$ e $1464 \mathrm{~cm}^{-1}$ correspondentes ao $\mathrm{CaCO}_{3}$ na forma de aragonita. ${ }^{10,11} \mathrm{~A}$ banda de absorção próxima a $2520 \mathrm{~cm}^{-1}$ que aparece nas três amostras indica a presença do radical $\mathrm{HCO}_{3}^{-}$residente no material. As bandas no espectro infravermelho da amostra de conchas de mexilhões (Figura 1B) que aparecem próximas a 2850 e $2920 \mathrm{~cm}^{-1}$ estão associadas aos diferentes modos vibracionais das espécies, $\mathrm{CH}$ e $\mathrm{NH}$ da matéria orgânica existente na amostra também detectada por análise elementar (CHN-S) Tabela 1. As bandas próximas a $3400 \mathrm{~cm}^{-1}$ que aparecem nos três espectros (Figura 1) correspondem ao estiramento $\mathrm{OH}$ da água, que deve ser proveniente da umidade na amostra.

\section{Degradação térmica por TGA}

A degradação térmica das amostras foi conduzida em um módulo termogravimétrico com aquecimento de $10{ }^{\circ} \mathrm{C} \min ^{-1}$ em atmosfera

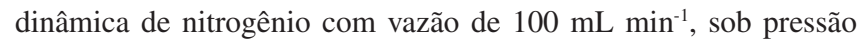
atmosférica. A temperatura máxima empregada foi de $810^{\circ} \mathrm{C}$, em suporte de amostra de platina usando $7 \pm 1 \mathrm{mg}$ de amostra.

Tabela 1. Análise elementar por CHN-S das conchas de ostras e de mexilhões, conforme os três pontos de amostragem considerados

\begin{tabular}{|c|c|c|c|c|c|c|}
\hline \multirow[t]{2}{*}{ Análise por $\mathrm{CHN}-\mathrm{S}$} & \multicolumn{3}{|c|}{ Conchas de Ostras/Localidade } & \multicolumn{3}{|c|}{ Conchas de Mexilhões/Localidade } \\
\hline & Enseada & Ganchos & Sambaqui & Enseada & Ganchos & Sambaqui \\
\hline Carbono total $(\%)$ & 12,09 & 11,95 & 11,94 & 13,40 & 13,52 & 13,76 \\
\hline Hidrogênio (\%) & ND & ND & ND & 0,49 & 0,57 & 0,58 \\
\hline Nitrogênio (\%) & 0,23 & 0,15 & 0,18 & 0,78 & 0,80 & 0,93 \\
\hline Enxofre $(\%)$ & ND & ND & ND & ND & ND & ND \\
\hline
\end{tabular}

ND: Não detectado 


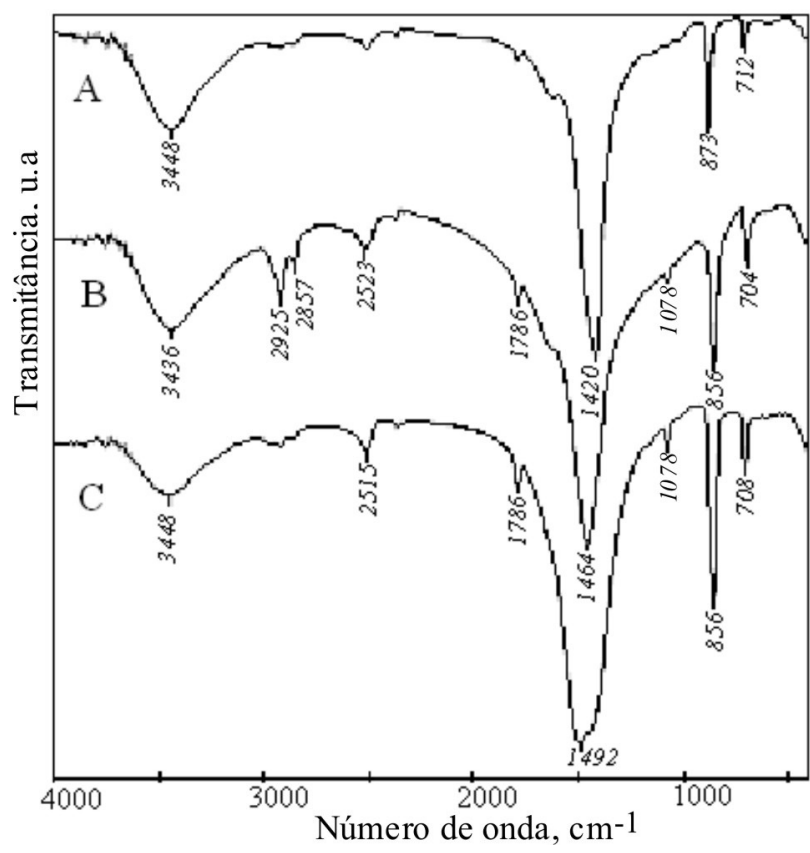

Figura 1. Espectro de absorção no infravermelho na faixa de 4000 a 400 $\mathrm{cm}^{-1}$, para amostras de: A) conchas de ostras; B) conchas de mexilhões; C) padrão de $\mathrm{CaCO}_{3}$

A degradação térmica por TGA das diferentes amostras de conchas de ostras e mexilhões exibe eventos distintos de perda de massa mostrados na Tabela 2.

As amostras das conchas de ostras apresentam a primeira perda de massa entre 1,2 a 1,9\%, na faixa de temperatura entre 327 a 400 ${ }^{\circ} \mathrm{C}$ (Tabela 2), correspondente à perda da fração orgânica. $\mathrm{O}$ segundo evento apresentou perda de massa entre 41,2 a 43,0\%, na faixa de temperatura entre 765 a $777{ }^{\circ} \mathrm{C}$, correspondente à degradação do carbonato de cálcio $\left(\mathrm{CaCO}_{3}\right)$, formando o óxido de cálcio e liberando de $\mathrm{CO}_{2}$. Acima desta temperatura não houve variação de massa, indicando que o material remanescente está na forma de óxido. Os teores dos óxidos resultantes ou de cinzas, determinados por diferença das porcentagens de perda de massa, variam entre 56,5 a $57,1 \%$.

Resultados similares foram obtidos por Checa et al. ${ }^{12}$ por degradação térmica de conchas de ostras de diferentes procedências. Os autores observaram dois eventos de perda de massa em temperaturas na faixa de 200 a $400{ }^{\circ} \mathrm{C}$ pela degradação da matéria orgânica e de 400 a $600{ }^{\circ} \mathrm{C}$ pela emissão de $\mathrm{CO}_{2}$, correspondendo à degradação de $\mathrm{CaCO}_{3}$.

As amostras das conchas de mexilhões também mostraram dois eventos de perda de massa (Tabela 2). A primeira degradação ocorreu na faixa de temperatura entre 319 e $332{ }^{\circ} \mathrm{C}$ e perda de massa variando entre 4,2 a $5,7 \%$, mais que o dobro quando comparado com a primeira perda de massa das amostras das conchas das ostras. A segunda degradação térmica ocorreu entre 788 a $796{ }^{\circ} \mathrm{C}$ com perda de massa entre 41,2 a 42,8\%, correspondente à degradação do carbonato de cálcio e liberação de $\mathrm{CO}_{2}$. Também não houve perda de massa acima desta temperatura nas conchas de mexilhões. Os teores dos óxidos resultantes ou de cinzas, determinados por diferença das porcentagens de perda de massa, variam entre 51,5 a $54,5 \%$.

A perda de massa no primeiro evento correspondendo à fração orgânica foi aproximadamente duas vezes maior nas conchas de mexilhões quando comparada às conchas de ostras. O segundo evento, correspondente à degradação do carbonato de cálcio e liberação de $\mathrm{CO}_{2}$, apresentou a mesma perda de massa para os dois tipos de conchas (de ostras e mexilhões) sugerindo teores similares de carbonato nas conchas dos dois moluscos.

Os dados obtidos por CHN-S mostrados na Tabela 1, para conchas de ostras e mexilhões apresentam teores de carbono, nitrogênio e hidrogênio em média $2,7 \%$ maiores nas conchas de mexilhões, concordando com os dados obtidos por TGA.

\section{Determinação de óxidos}

A determinação do teor total de óxidos foi feita por espectrometria de fluorescência de raios X (FRX) com amostras sólidas com granulometria de 80 mesh, após serem calcinadas a $1000{ }^{\circ} \mathrm{C}$.

A Tabela 3 mostra os valores em percentagem do teor dos diferentes óxidos nas amostras de conchas de mexilhões e ostras. Os dados identificam o óxido de cálcio $(\mathrm{CaO})$ como majoritário, sendo $56,10 \%$ na amostra de conchas de ostras, contra 53,80\% na amostra de conchas de mexilhões. O teor de óxido de cálcio na amostra de conchas determinado por FRX apresentou valores similares aos determinados por TGA, Tabela 2.

Os demais óxidos determinados conforme Tabela 3 apresentam valores menores de $1 \%$, sendo em maior quantidade nas amostras de conchas de ostra, exceto para o óxido de estrôncio que é levemente maior nas conchas de mexilhões seguindo a seguinte ordem:

Majoritário (Ostra e Mexilhão): $\mathrm{CaO}$.

Minoritários (Ostra): $\mathrm{Na}_{2} \mathrm{O}>\mathrm{SiO}_{2}>\mathrm{MgO}>\mathrm{Al}_{2} \mathrm{O}_{3}>\mathrm{P}_{2} \mathrm{O}_{5}>\mathrm{SrO}>$ $\mathrm{K}_{2} \mathrm{O}>\mathrm{Fe}_{2} \mathrm{O}_{3}$.

Minoritários (Mexilhão): $\mathrm{Na}_{2} \mathrm{O}>\mathrm{SiO}_{2}>\mathrm{MgO}>\mathrm{Al}_{2} \mathrm{O}_{3}>\mathrm{SrO}>$ $\mathrm{P}_{2} \mathrm{O}_{5}>\mathrm{K}_{2} \mathrm{O} ; \mathrm{TiO}_{2}$.

O teor de óxido de cálcio para as amostras de conchas de ostras e mexilhões está dentro da faixa determinada por TGA mostrado na Tabela 2 para as várias amostras analisadas.

\section{Determinação de metais}

A Tabela 4 apresenta os resultados da análise do teor de metais nas amostras de conchas de ostras e mexilhões determinados pela técnica de espectrometria de absorção atômica, chama e forno de grafite.

O cálcio apresenta-se como o elemento majoritário, entre 33 a $34,8 \%$ independente do local de coleta das amostras, sendo ligeiramente superior nas conchas de ostra. Este resultado era esperado considerando-se que a estrutura e constituição da concha é predominantemente carbonato de cálcio, tanto nas conchas de ostra como nas conchas de mexilhões.

As principais diferenças em termos de concentração dos metais

Tabela 2. Temperaturas de degradação térmica TGA, de amostras de conchas de ostra e mexilhões com respectivas perdas de massa em dois eventos distintos

\begin{tabular}{|c|c|c|c|c|c|c|}
\hline \multirow[t]{2}{*}{ Degradação Térmica } & \multicolumn{3}{|c|}{ Conchas de Ostras/Localidade } & \multicolumn{3}{|c|}{ Conchas de Mexilhões/Localidade } \\
\hline & Enseada & Ganchos & Sambaqui & Enseada & Ganchos & Sambaqui \\
\hline $1^{\text {a }}$ Perda de massa, & $1,94 \%$ & $1,21 \%$ & $1,73 \%$ & $4,25 \%$ & $5,06 \%$ & $5,66 \%$ \\
\hline Pico máximo & $327^{\circ} \mathrm{C}$ & $342{ }^{\circ} \mathrm{C}$ & $400{ }^{\circ} \mathrm{C}$ & $325^{\circ} \mathrm{C}$ & $332{ }^{\circ} \mathrm{C}$ & $319^{\circ} \mathrm{C}$ \\
\hline $2^{a}$ Perda de massa, & $41,51 \%$ & $41,98 \%$ & $41,18 \%$ & $41,21 \%$ & $41,20 \%$ & $42,78 \%$ \\
\hline Pico máximo & $777^{\circ} \mathrm{C}$ & $777^{\circ} \mathrm{C}$ & $765^{\circ} \mathrm{C}$ & $788^{\circ} \mathrm{C}$ & $796^{\circ} \mathrm{C}$ & $792{ }^{\circ} \mathrm{C}$ \\
\hline Perda total $\%$ & 43,45 & 43,19 & 42,91 & 45,46 & 46,26 & 48,44 \\
\hline Total de óxidos \% & 56,55 & 56,81 & 57,09 & 54,54 & 53,74 & 51,56 \\
\hline
\end{tabular}


Tabela 3. Percentual de óxidos em amostras de conchas de ostras e mexilhões determinados pela técnica de fluorescência de raios $\mathrm{X}$

\begin{tabular}{lcccccccccccc}
\hline Óxidos & $\mathrm{SiO}_{2}$ & $\mathrm{Al}_{2} \mathrm{O}_{3}$ & $\mathrm{Fe}_{2} \mathrm{O}_{3}$ & $\mathrm{CaO}$ & $\mathrm{Na}_{2} \mathrm{O}$ & $\mathrm{K}_{2} \mathrm{O}$ & $\mathrm{MnO}$ & $\mathrm{TiO}_{2}$ & $\mathrm{MgO}$ & $\mathrm{P}_{2} \mathrm{O}_{5}$ & $\mathrm{SrO}$ & $\mathrm{CaO}$ \\
\hline C. Ostra & 0,91 & 0,42 & 0,05 & 48,3 & 0,98 & 0,07 & $\mathrm{ND}$ & 0,03 & 0,68 & 0,15 & 0,13 & 56,10 \\
C. Mexilhão & 0,35 & 0,18 & $\mathrm{ND}$ & 47,9 & 0,82 & 0,02 & $\mathrm{ND}$ & 0,02 & 0,22 & 0,04 & 0,16 & 53,80 \\
\hline
\end{tabular}

ND: Não detectado

Tabela 4. Teores de metais nas amostras de conchas de ostras e mexilhões determinados por AAS-Chama e AAS-FG

\begin{tabular}{|c|c|c|c|c|c|c|}
\hline \multirow[t]{2}{*}{ Metal } & \multicolumn{3}{|c|}{ Conchas de Ostras/Localidade } & \multicolumn{3}{|c|}{ Conchas de Mexilhões/Localidade } \\
\hline & Enseada & Ganchos & Sambaqui & Enseada & Ganchos & Sambaqui \\
\hline $\mathrm{Ca}(\%)$ & 34,31 & 34,83 & 34,87 & 33,05 & 32,47 & 33,11 \\
\hline $\mathrm{Mg}(\mathrm{mg} / \mathrm{kg})$ & $2.687,35$ & $2.789,40$ & $2.824,47$ & 464,17 & $1.080,63$ & 435,35 \\
\hline $\mathrm{Sr}(\mathrm{mg} / \mathrm{kg})$ & 867,08 & 866,40 & 836,36 & $1.120,96$ & $1.132,78$ & $1.426,99$ \\
\hline $\mathrm{Fe}(\mathrm{mg} / \mathrm{kg})$ & 360,72 & 483,78 & 145,98 & 478,09 & 683,5 & 669,62 \\
\hline $\mathrm{Na}(\mathrm{mg} / \mathrm{kg})$ & 81,80 & 81,80 & 71,16 & 60,36 & 63,93 & 55,89 \\
\hline $\operatorname{Mn}(\mathrm{mg} / \mathrm{kg})$ & 42,29 & 45,54 & 19,15 & 25,90 & 35,87 & 23,28 \\
\hline $\mathrm{Cr}(\mathrm{mg} / \mathrm{kg})$ & 3,82 & 1,91 & 2,77 & 80,23 & 71,07 & 79,86 \\
\hline $\mathrm{Zn}(\mathrm{mg} / \mathrm{kg})$ & 9,29 & 5,96 & 5,3 & 3,34 & 11,32 & 6,56 \\
\hline $\mathrm{K}(\mathrm{mg} / \mathrm{kg})$ & 4,10 & 3,03 & 2,46 & 1,53 & 1,24 & 1,24 \\
\hline Ní (mg/kg) & 1,77 & 0,79 & 1,14 & 6,16 & 1,63 & 2,56 \\
\hline $\mathrm{Cu}(\mathrm{mg} / \mathrm{kg})$ & 1,81 & 2,18 & 1,21 & 2,70 & 3,23 & 1,66 \\
\hline $\mathrm{Pb}(\mathrm{mg} / \mathrm{kg})$ & 0,41 & 0,30 & 0,25 & 0,75 & 1,46 & 0,43 \\
\hline $\mathrm{Cd}(\mathrm{mg} / \mathrm{kg})$ & 0,03 & 0,02 & 0,02 & 0,03 & 0,03 & 0,03 \\
\hline
\end{tabular}

aparecem nos níveis de $\mathrm{Cr}$ e $\mathrm{Mg}$ quando comparamos as conchas de mexilhões e ostras. As conchas dos mexilhões acumulam o $\mathrm{Cr}$ num fator de até 40 vezes mais que as conchas de ostras, em todos os pontos de cultivo estudados. No entanto, quando comparamos as concentrações de $\mathrm{Mg}$, encontramos que a quantidade deste elemento é quase 6 vezes maior nas conchas de ostra do que nas de mexilhões. $\mathrm{O}$ estrôncio acumula-se mais em conchas de mexilhões, porém em proporções menores de 1,7 vezes e o sódio se acumula mais nas conchas de ostras, sendo esta diferença pequena.

Trabalhos como os de Thorn et al. ${ }^{6}$ e Almeida et al. ${ }^{7}$ sugerem que além do cálcio, vários outros elementos são incorporados à estrutura das conchas cujas porcentagens estão relacionadas à temperatura, $\mathrm{pH}$, salinidade e concentração destes componentes na água do meio em que habitam. Desta forma, as conchas de moluscos bivalves poderiam ser usadas como bioindicadores para detectar modificações na composição da água por atividades antropogênicas ou de origem natural por atividades geológicas.

Curtius et al. ${ }^{13}$ apresentaram dados da concentração de alguns metais e semimetais de amostras de água e dos moluscos coletados em três pontos de cultivo da região litorânea da Ilha de Santa Catarina, os mesmos locais de coleta utilizados neste trabalho.

As análises foram de amostras da fração dissolvida e da fração particulada da água do mar e do próprio molusco seco, ambos coletados nos mesmos locais de amostragem descritos neste trabalho. Estes dados, no entanto, não permitem traçar uma relação direta entre a concentração dos metais encontrados nas amostras de conchas de ostras e mexilhões neste trabalho com as concentrações de metais encontrados na água do mar e em moluscos secos apresentados no trabalho de Curtius et al. ${ }^{13}$

Os dados de Curtius et al. ${ }^{13}$ e os dados obtidos neste trabalho são de amostras de conchas e dos moluscos provenientes de cultivos que possuem no máximo 6 meses de vida. Talvez seja pouco tempo para tentar traçar uma relação direta entre as concentrações de metais no molusco, nas conchas e na água no meio em que vivem. Geralmente moluscos que se desenvolvem em ambiente não controlado possuem crescimento muito mais lento facilitando, desta forma, a incorporação de metais na estrutura de suas conchas. Este pode ser um dos fatores que não permitem traçar uma relação direta, conforme sugerido por outros autores ${ }^{6,7}$ entre a concentração dos metais encontrados nas amostras de conchas de ostras e mexilhões com a concentração destes metais na água do mar e no próprio molusco, apresentados no trabalho de Curtius et al.. ${ }^{13}$

\section{Estrutura cristalina}

As medidas de difração de raios $\mathrm{X}$ foram obtidas pelo método do pó, em difratômetro Philips X’Pert, com radiação $\mathrm{Cu} \mathrm{K} \alpha$, com $\lambda=1,54056 \AA$. A identificação das fases cristalinas foi obtida por comparação com a base de dados do International Center for Diffraction Data $(I C D D) .{ }^{14}$

A análise quantitativa da composição cristalina do carbonato de cálcio das conchas de ostras e mexilhões foi obtida através do método de Rietveld, por comparação da base de dados do Inorganic Crystal Structure Database - ICSD. ${ }^{15}$

Os difratogramas de raios $\mathrm{X}$ obtidos das amostras de conchas de ostras e mexilhões estão apresentados nas Figuras 1S e 2S (material suplementar), respectivamente. Em ambas as amostras analisadas, o carbonato de cálcio é o constituinte principal da fase cristalina, sendo a concha de ostra composta exclusivamente por estrutura cristalina de calcita, ao passo que a concha de mexilhão consiste de $93 \%$ de aragonita e $7 \%$ de calcita.

Os dados de infravermelho (Figura 1) das amostras de conchas de ostras e mexilhões também apresentaram resultados similares aos obtidos por difração de raios $\mathrm{X}$ relacionados à estrutura cristalina do carbonato de cálcio constituinte das conchas.

A porcentagem de aragonita/calcita na microestrutura e orientação cristalina das conchas de moluscos pode variar dependendo do molusco e da região onde se desenvolve. Trabalhos como o de Chateignera et $a l .{ }^{4}$ sobre microestrutura de conchas de moluscos e textura cristalográfica mostram que nem sempre é possível determinar com certeza as diferentes proporções cristalinas das conchas.

\section{Análise microestrutural}

As imagens das micrografias por microscopia eletrônica de varredura (MEV) e a análise química por energia dispersiva de raios $\mathrm{X}$ 
das superfícies das conchas de ostras e mexilhões estão apresentadas a seguir.

A análise química por energia dispersiva de raios $\mathrm{X}$ das superfícies das conchas de ostra e mexilhões apresenta alta concentração de cálcio e em proporções bem menores carbono e oxigênio, provavelmente provenientes de matéria orgânica e umidade, Figura 3SA e B (material suplementar). As conchas de ostra apresentam também outros elementos em sua superfície, como magnésio, sódio, cloro, alumínio, ferro e silício, que podem estar incorporados à estrutura da concha ou serem provenientes de material aderido a sua superfície. O silício, em alguns casos, pode aparecer como um sinal intrínseco do equipamento, quando este possui silício na composição do detector; no entanto, nestas análises o pico é relativamente grande, o aparelho foi calibrado com padrão específico e não apresenta pico relacionado ao silício.

A Figura 2 mostra imagens da superfície por MEV obtidas de diferentes formas de conchas de ostra. A Figura 2A mostra incrustação de outra espécie de concha na superfície, as Figuras 2B e D mostram a camada externa da concha e as Figuras $2 \mathrm{C}, \mathrm{D}, \mathrm{F}$ mostram fraturas no corpo das conchas exibindo camadas internas em forma de lamelas, que compõem as estruturas cristalina das conchas, basicamente calcita na forma de carbonato de cálcio $\left(\mathrm{CaCO}_{3}\right)$. Essas estruturas em camadas são resultados da biomineralização realizada por proteínas.

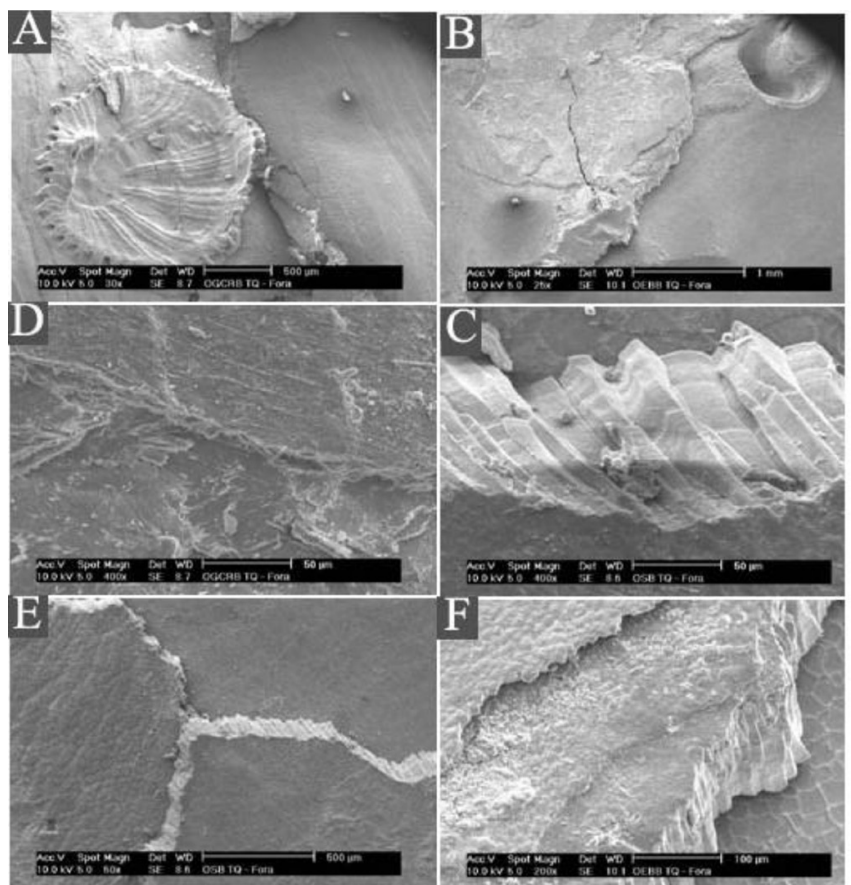

Figura 2. Imagens da superfície de conchas de ostra obtidas por MEV. A: incrustação na superfície externa de outra espécie de concha; B e D: camada externa; C, E e F: fratura exibindo camadas internas em forma de lamelas

A Figura 3 mostra imagens da superfície por MEV obtidas de diferentes formas de conchas de mexilhões. A Figura 3G mostra a camada externa da concha com desenhos que se repetem ao longo da superfície. A Figura $3 \mathrm{~K}$ mostra a superfície externa da concha onde aparecem fibras sugerindo material orgânico usadas pelo molusco para a sua fixação. A Figura 3I mostra a superfície interna da concha, a camada nacarada e as Figuras 3J e L mostram com detalhes a estrutura do nácar exibindo tabletes poligonais típicos de cristais de aragonita. A Figura $3 \mathrm{H}$ mostra em detalhes as lamelas sobrepostas que formam o corpo da concha constituída por agregados de placas de aragonita, depositadas em lâminas ou colunas.
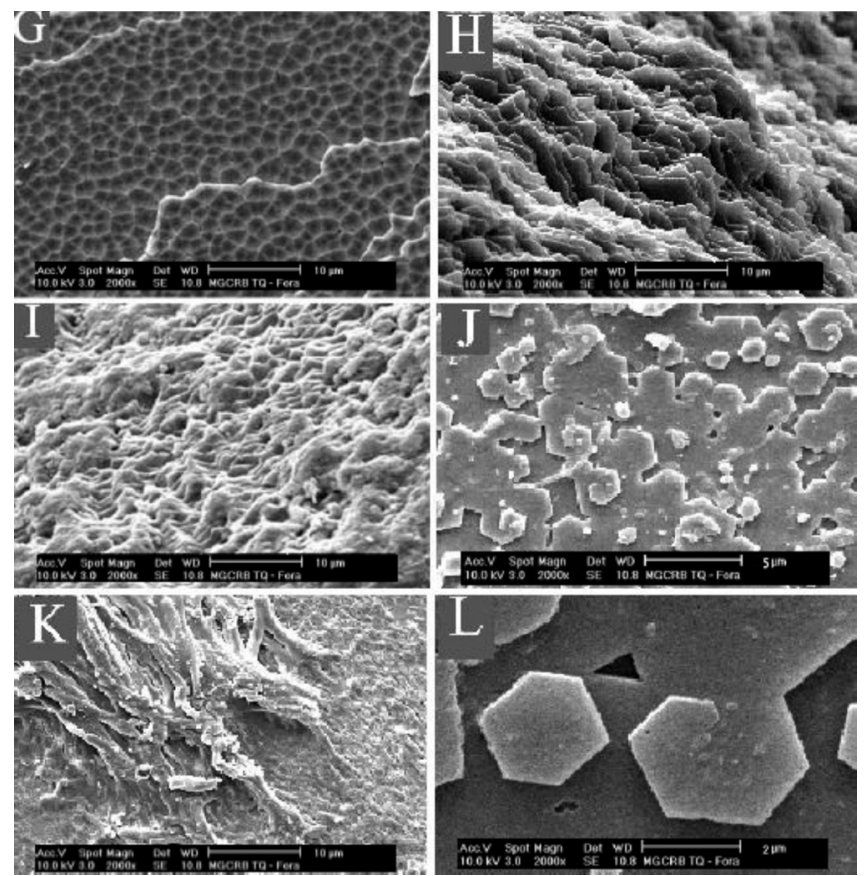

Figura 3. Imagens da superfície de conchas de mexilhões obtidas por MEV. G: camada da superfície externa; $H$ : camadas constituídas por agregados de placas de aragonita; I: camada nacarada; K: camada exibindo fibras de fixação do molusco; J, L: camada nacarada exibindo tabletes poligonais de aragonita

\section{Caracterização física}

As conchas de mexilhões apresentaram valores de densidade superiores às conchas de ostras. Os valores variaram de 1,50 a 1,61 $\mathrm{g} / \mathrm{cm}^{3}$ para as conchas de ostras e oscilaram entre 2,34 e $2,39 \mathrm{~g} / \mathrm{cm}^{3}$ nas conchas de mexilhões, Tabela 1S (material suplementar). As duas espécies de conchas possuem composição química semelhante, pois ambas as matrizes contêm majoritariamente $\mathrm{CaCO}_{3}$, o que muda é a forma dos cristais. Os cristais aciculares de aragonita são propensos a formar conjuntos entrelaçados, aumentando sua densidade. Desta maneira, o material policristalino de aragonita apresenta um considerável aumento de solidez ou maior resistência à quebra. ${ }^{10,11} \mathrm{Na}$ aragonita, o sistema cristalino é ortorrômbico (conchas de mexilhões) e na calcita, apresenta-se trigonal (conchas de ostras) acentuando também a sua porosidade.

A suspensão de $10 \%$ do pó de conchas em água apresentou pH próximo a 9, tanto para as conchas de mexilhões bem como para as conchas de ostras, ficando inferior ao $\mathrm{pH}$ do hidróxido de cálcio em água que é de 12,8 .

$\mathrm{O}$ índice de umidade das amostras de conchas trituradas variou entre 0,55 a $1,22 \%$ para as duas espécies.

\section{CONCLUSÃO}

Os resultados mostram que as conchas de ostras e mexilhões possuem diferenças significativas quanto às características microestruturais (estrutura cristalina). O carbonato de cálcio nas conchas de ostras apresenta estrutura cristalina $100 \%$ de calcita, enquanto nas conchas de mexilhões a estrutura cristalina de aragonita/calcita se apresenta na proporção de 93 e 7\%, respectivamente.

A composição química relacionada a metais não apresenta variações significativas sendo mais acentuadas as proporções de magnésio nas conchas de ostras e de estrôncio nas conchas de mexilhões. Independentemente do local de coleta, não se verificaram diferenças 
quanto às constituições química e física para a mesma espécie de molusco. As diferenças básicas são os parâmetros físicos como o tipo de estrutura cristalina, a densidade e o teor de matéria orgânica.

O elevado teor de cálcio, assim como baixos níveis de outros metais, são indicadores do potencial de aproveitamento desse material considerado resíduo.

\section{MATERIAL SUPLEMENTAR}

Está disponível em http://quimicanova.sbq.org.br, na forma de arquivo .PDF, com acesso livre.

\section{AGRADECIMENTOS}

Ao Departamento de Engenharia Sanitária e Ambiental e ao Departamento de Química da Universidade Federal de Santa Catarina, em especial à Central de Análises.

\section{REFERÊNCIAS}

1. Ferreira, J. F.; Magalhães, A. R. M.; VI Congresso Latinoamericano de Ciencias Del Mar, Mar del Plata, Argentina, 1995.

2. Poli, C. R. Em Aquicultura: Experiências Brasileiras; Poli, C. R.; Poli, A. T. B.; Andreatta, E.; Beltrame, E., orgs.; Multifatorial Editora: Florianópolis, 2004.
3. http://www.fundacentro.sc.gov.br/acquaforum/principal/ver_noticias. php?not=1974, acessada em Dezembro 2009.

4. Chateigner, D.; Hedegaard, C.; Wenk, H. R.; J. Struc. Geol. 2000, 22, 1723 .

5. Wheeler, A. P. Em Hard tissue mineralization and determination; Suga, S.; Watabe, N.; eds.; Springer-Verlag: Tokyo, 1992.

6. Thorn, K.; Cerrato, R. M.; Rivers, M. L.; Biol. Bull. 1995, $188,57$.

7. Almeida, M. J.; Moura, G.; Pinheiro, T.; Machado, J.; Coimbra, J.; Aquat. Toxicol. 1998, 40, 323.

8. Silva, D.; Dissertação de Mestrado, Universidade Federal de Santa Catarina, Brasil, 2007

9. Kwon, H.; Chan-Won, L.; Byung-Sei, J.; Jon-Do, Y.; Koopman, B.; Resour. Conserv. Recycl. 2004, 41, 75.

10. Bessler, K. E.; Rodrigues, L. C.; Quim. Nova 2008, 31, 178.

11. Chakrabarty, D.; Mahapatra, S.; J. Mater. Chem. 1999, 9, 2953

12. Checa, A. G.; Rodrıguez-Navarro, A. B.; Esteban-Delgado, F. J.; Biomaterials 2005, 26, 6404.

13. Curtius, A. J.; Seibert, E. L.; Fiedler, H. D.; Ferreira, J. F.; Vieira, P. H. F.; Quim. Nova 2003, 26, 44.

14. International Center for Diffraction Data (ICDD); Joint Committee of Powder Diffraction Standards (JCPDS): Pennsylvania, 1998.

15. Inorganic Crystal Structure Database (ICSD); Gmchin-Intitut fur Anorganishe Chemie and Fachinformationzentrum (FIZ): Karlsruhe, 1995. 


\section{CARACTERIZAÇÃO FÍSICO-QUÍMICA E MICROESTRUTURAL DE CONCHAS DE MOLUSCOS BIVALVES PROVENIENTES DE CULTIVOS DA REGIÃO LITORÂNEA DA ILHA DE SANTA CATARINA}

Denyo Silva e Nito Angelo Debacher*

Departamento de Química, Universidade Federal de Santa Catarina, 88040-900 Florianópolis - SC, Brasil Armando Borges de Castilhos Junior e Fabio Rohers

Departamento de Engenharia Sanitária e Ambiental, Universidade Federal de Santa Catarina, 88040-970 Florianópolis - SC, Brasil

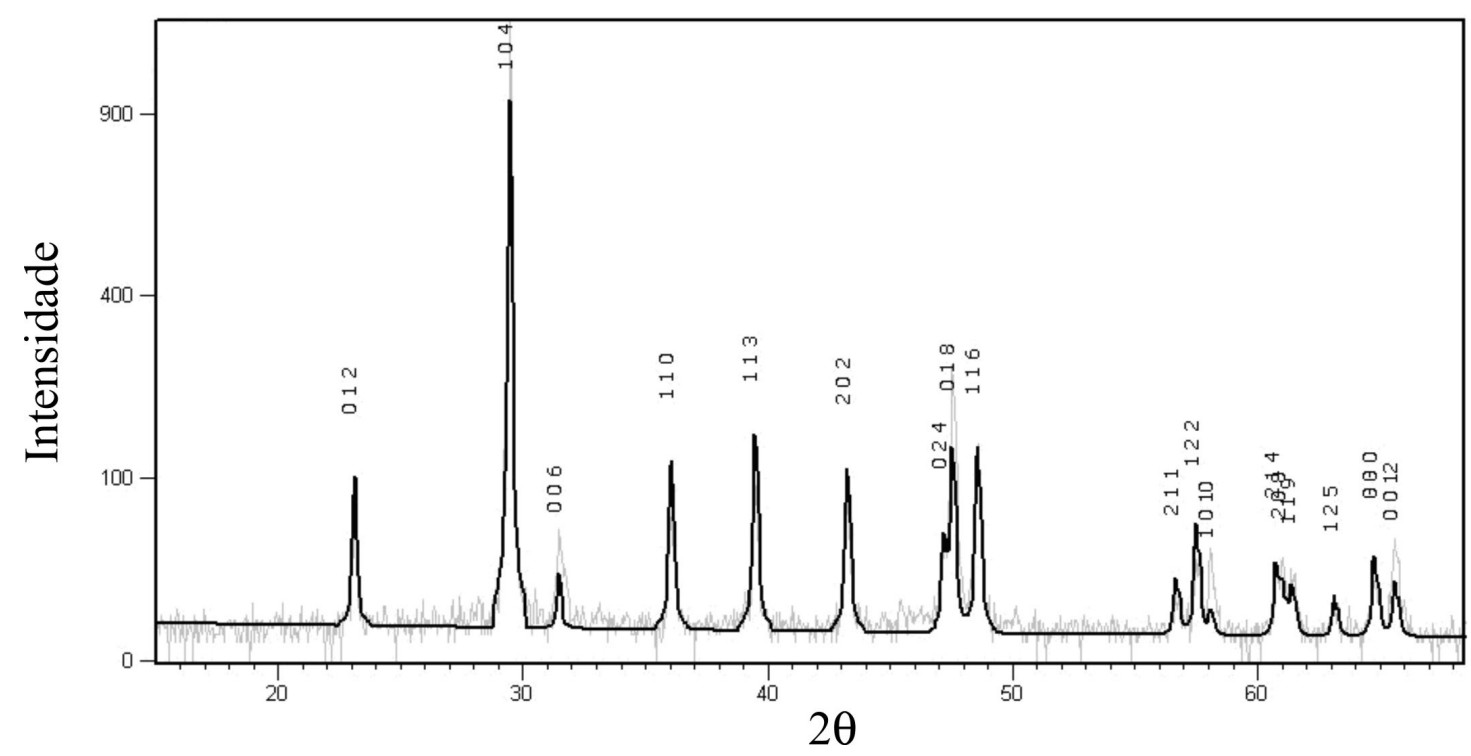

Figura 1S. Medidas de difração de raios X obtido das amostras de conchas de ostras

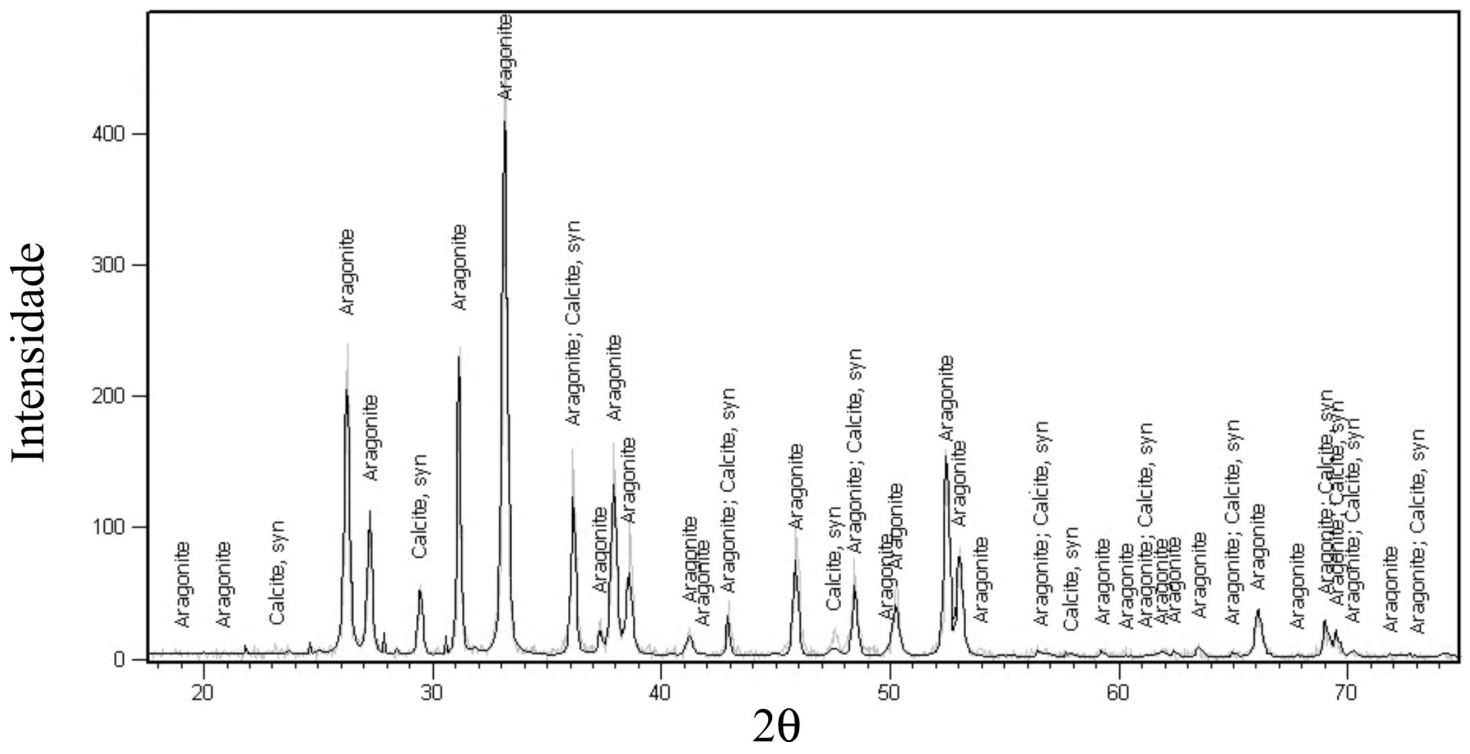

Figura 2S. Medidas de difração de raios X obtido das amostras de conchas de mexilhões 


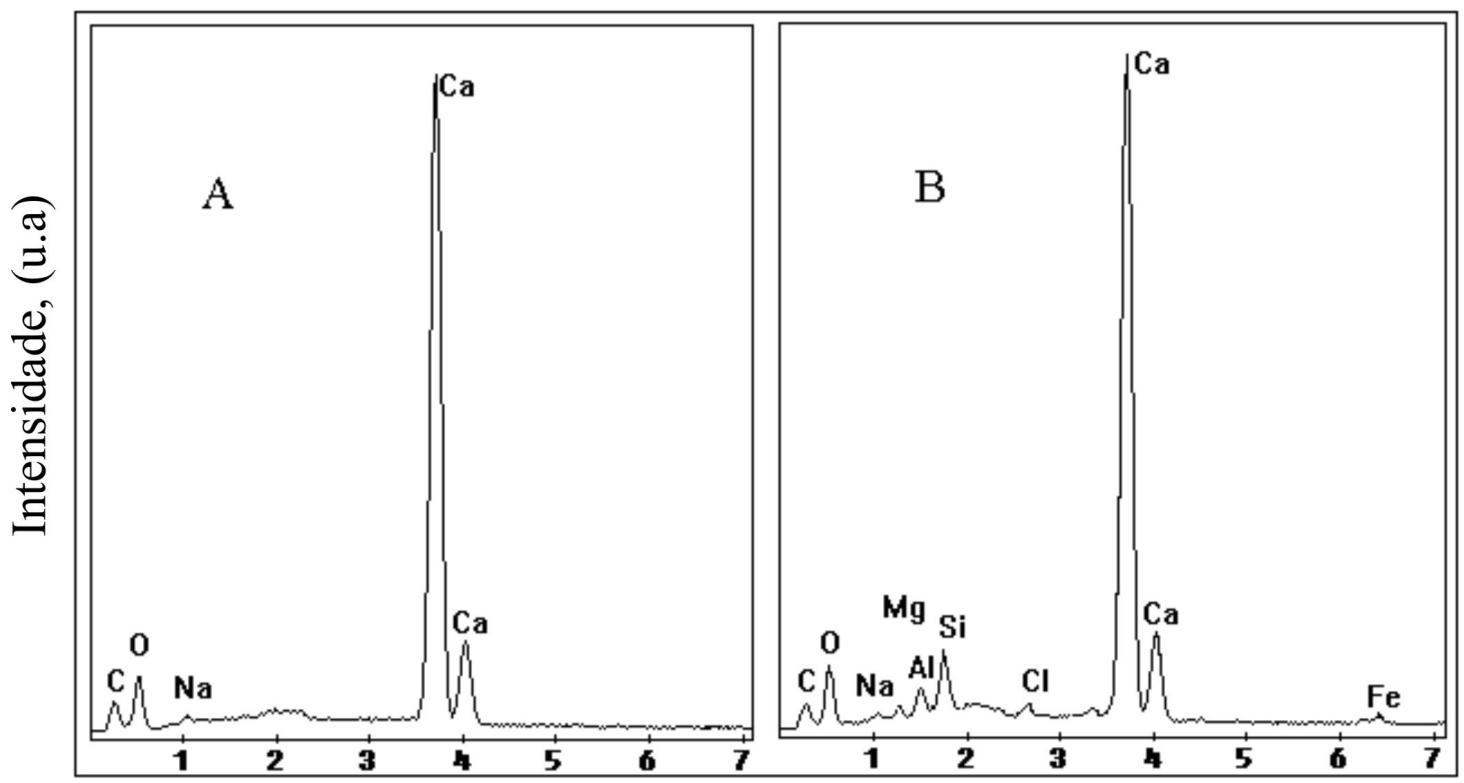

Energia, $\mathrm{kV}$

Figura 3S. Análise química por energia dispersiva de raios $X$ das amostras de conchas de mexilhões $(A)$ e conchas de ostras (B) 